\title{
ANTICONVULSANT ACTIVITY OF CITRUS MAXIMUS LEAVES IN EXPERIMENTAL ANIMAL MODELS
}

\author{
Nishanta Thakuria ${ }^{1 *}$, Swarnamoni Das ${ }^{2}$, Babul Dewan ${ }^{1}$ \\ ${ }^{1}$ Department of Pharmacology, Silchar Medical College and Hospital, Silchar, Assam, India. ${ }^{2}$ Department of Pharmacology, Assam Medical \\ College and Hospital, Dibrugarh, Assam, India. Email: dr.nyshanta@yahoo.co.in
}

Received: 09 August 2016, Revised and Accepted: 29 August 2016

\section{ABSTRACT}

Objective: To assess the anticonvulsant activity of ethanolic extract of Citrus maximus (EECM) leaves of maximal electroshock seizure (MES) and pentylenetetrazol (PTZ)-induced seizure models on albino (Wistar strain) rats and mice.

Methods: Anticonvulsant activity was carried out by MES model and PTZ-induced clonic convulsions model; in each model, albino rats (Wistar strain) of either sex were taken and divided into five groups, each consisting of 6 rats. One group was used as control (3\% w/v gum acacia), one as standard (phenytoin), and three groups for the test drug of EECM leaves (doses of 50, 100, and $200 \mathrm{mg} / \mathrm{kg}$ ) treatment. The reduction in time or abolition of tonic extensor phase of MES-convulsions was recorded for all the animals. In PTZ model, either delay or complete abolition of convulsions in rats treated with diazepam and EECM leaves was noted for all the animals.

Result: EECM leaves reduced the extensor phase of convulsion in MES in a dose-dependent manner and decrease in the duration of convulsions in PTZ model with increasing dose. Anticonvulsant activity was seen maximum at the dose of $200 \mathrm{mg} / \mathrm{kg}$.

Conclusions: Thus, from the above two seizure models of MES and PTZ, it can be concluded that EECM leaves have got an anticonvulsant effect in an increasing dose-dependent manner.

Keywords: Anticonvulsant, Citrus maximus, Maximal electroshock seizure, Pentylenetetrazol.

\section{INTRODUCTION}

Epilepsy describes a condition, in which a person has recurrent seizures due to a chronic, underlying process. This implies that a person with a single seizure, or recurrent seizures due to correctable or avoidable circumstances, does not necessarily have epilepsy. Epilepsy refers to a clinical phenomenon rather than a single disease entity. Since there are many forms and causes of epilepsy. However, among the many causes of epilepsy, there are various epilepsy syndromes, in which the clinical and pathological characteristics are distinctive and suggest a specific underlying etiology [1].

Citrus maximus is commonly known as pomelo (English), rabab-tenga (Assamese), Chinese grapefruit, pummelo, pummel jabot, shaddock, or Jeruk Bali. It is a citrus fruit which belongs to the Rutaceae family and is usually pale green to yellow when ripe, with sweet flesh and thick spongy ring [2].

C. maximus has been used in the traditional medicine in Asia for 100 of years. The decoctions of the leaves, flowers, and rind are used for their sedative effect in cases of epilepsy, chorea, and severe cough. The hot leaf decoction is applied on swellings and ulcers. The fruit juice is taken as a febrifuge. The sarcocarps are employed against coughs, dyspepsia, and lumbago. The pulp is considered an effective aid in the treatment of urinary disorders. Leaf extractions have shown antibiotic activity [3]. Traditional medicinal plants with various active principles and properties have been used since ancient times by physicians and laymen to treat a variety of diseases such as epilepsy. The anticonvulsant activity of Citrus maximus leaves has not been studied earlier in the north-eastern region of India. Keeping in view with the above ideas, the present study has been undertaken to evaluate the anticonvulsant activity of $C$. maximus leaves in albino rats and mice, respectively.

\section{METHODS}

\section{Collection of plant material}

C. maximus leaves were collected from the PG-Hostel campus of Assam Medical College, Dibrugarh, in the month of March and identified by Botanist, Department of Life Sciences, Dibrugarh University, Dibrugarh, Assam, India, with identification voucher number being DU/LS/208.

\section{Method of extraction}

The required amount of leaves of $C$. maximus was collected and dried at room temperature. The dried leaves were ground into powder separately. Sufficient amount of powdered leaves was moistened with 95\% ethyl alcohols and allowed to remain for $6 \mathrm{hrs}$ in a percolator. When the liquid began to drop from the percolator, the orifice was closed and the content was allowed to macerate for $24 \mathrm{hrs}$. After $24 \mathrm{hrs}$, it was allowed to percolate slowly, a rate not exceeding $1 \mathrm{ml} /$ minutes [4] and the solution was collected in Petri dishes. Alcohol was allowed to evaporate at room temperature. When the extract got completely dried, it was scrapped out, weighed and stored [4] and the yield at the end of extraction was found to be $16.7 \mathrm{~g}$.

\section{Acute toxicity testing}

In the present study, for acute toxicity testing for both oral (not intended route) and intraperitoneal (i.p.) (intended route), routes were performed. Oral acute toxicity testing was studied in albino mice as well as in albino rats according to the OECD Guidelines for 425 [5], and no mortality was recorded up to the dose of $2000 \mathrm{mg} / \mathrm{kg}$.

\section{Grouping and preparation of drug doses}

a. Vehicle (Group A): 3\% (w/v) gum acacia suspension was prepared and used in the control group.

b. Test drugs (Group $\mathrm{B}_{1}$, Group $\mathrm{B}_{2}$, and Group $\mathrm{B}_{3}$ ): 50, 100, and $200 \mathrm{mg} / \mathrm{kg}$ of the ethanolic extract of C. maximus (EECM) leaves were prepared with $3 \%(\mathrm{w} / \mathrm{v})$ gum acacia as a suspending agent.

c. Standard drugs (Group C): For anticonvulsant models-phenytoin $25 \mathrm{mg} / \mathrm{kg}$, and diazepam $4 \mathrm{mg} / \mathrm{kg}$. All the suspensions of phenytoin and diazepam were prepared with $3 \%(\mathrm{w} / \mathrm{v})$ gum acacia.

d. CNS stimulant: Pentylenetetrazol (PTZ) $40 \mathrm{mg} / \mathrm{kg}$ [6], a stock solution containing $4 \mathrm{mg} / \mathrm{ml}$ of the drug was prepared using distilled water. 


\section{EXPERIMENTAL PROCEDURES}

Permission of the Institutional Animal Ethical Committee was obtained before conducting the study.

\section{Maximal electroshock seizure (MES) model}

Induction of the MES, using an electroconvulsiometer, is a commonly used model for evaluation of anticonvulsant drugs.

Healthy albino rats (Wistar strain) of either sex were taken and divided into five groups, each consisting of 6 rats. One group was used as control ( $3 \% \mathrm{w} / \mathrm{v}$ gum acacia), one as standard (phenytoin), and three groups for the test drug (EECM in the doses of 50, 100, and $200 \mathrm{mg} / \mathrm{kg}$ ) treatment.

- Each animal was properly held, and earlobe electrodes were placed on the earlobes and current of $150 \mathrm{~mA}$ was passed for 0.2 seconds. Different stages of convulsions as mentioned earlier were noted down, along with the time (seconds) spent by the animal in each phase of the convulsions. The same procedure was repeated with other animals of the control group. The current was passed 30 minutes after i.p. injection of $3 \%(w / v)$ gum acacia.

- For the test drug groups, the same procedure as the earlier step was repeated for three different doses $(50,100$, and $200 \mathrm{mg} / \mathrm{kg}$, i.p.) of EECM.

- Phenytoin (standard) was also injected i.p. to all the 6 rats. After waiting for 30 minutes, animals were subjected to electroconvulsions as described in the earlier steps.

- The reduction in time or abolition of tonic extensor phase of MESconvulsions was recorded for all the animals [7].

\section{PTZ-induced clonic convulsions}

Healthy albino rats (Wistar strain) of either sex were taken and divided into five groups, each consisting of 6 rats. One group as a control, one as standard (diazepam), and three as tests (EECM in the doses of 50, 100, and $200 \mathrm{mg} / \mathrm{kg}$ ) were taken for the study.

- $3 \%(\mathrm{w} / \mathrm{v})$ gum acacia was injected intraperitoneally to the control animals, and after 30 minutes, PTZ was injected subcutaneously to these animals, and the onset of action (indicated by Straub's tail, jerky movements of the whole body and convulsions) and severity of convulsions due to the drug were noted.

- EECM in the doses of 50,100, and $200 \mathrm{mg} / \mathrm{kg}$ were taken as test drug groups, and the same procedure as the earlier step was followed.

- Diazepam was injected intraperitoneally to a group of 6 rats, which were taken as the standard group. After waiting for 30 minutes, the animals were subjected to subcutaneous injection of PTZ as described in the earlier step.

- Either delay or complete abolition of convulsions in rats treated with diazepam and EECM was noted [7].

\section{RESULTS}

\section{Statistical analysis}

The data were statistically analyzed using one-way analysis of variance (ANOVA) test, followed by Dunnett's multiple-comparison test, using the GraphPad Prism 5 software (Tables 1 and 2).

\section{DISCUSSION}

The present study was undertaken to evaluate an anticonvulsant activity of the EECM leaves in experimental animal models.

Although the MES test predicts activity against generalized tonic-clonic and cortical focal seizures and the PTZ test against absence seizures, the underlying neuronal abnormality is not well understood. Diminution of brain GABA level has been reported after subconvulsive dose of PTZ [8]

The MES-induced convulsions for the screening of the anticonvulsant drug are the standard experimental model for evaluating a drug in experimental animals its anticonvulsant property, which represents grand mal epilepsy in human beings [7].

The anticonvulsant effect by the MES model is determined by the effect of the drug in the tonic hindlimb extensor phase of the convulsion [9] By either completely abolishing it or by reducing its duration [7]. In the present study, it was found that the duration of the extensor phase in the control group was $12.5 \pm 0.428$ seconds, which is similar to that found by Manocha et al. [10] as $15.34 \pm 0.93$ seconds, Rewari and Prabhu [11] as

Table 1: MES model

\begin{tabular}{|c|c|c|c|c|c|c|c|c|c|}
\hline \multirow[t]{2}{*}{ S. No. } & \multirow[t]{2}{*}{ Groups } & \multirow{2}{*}{$\begin{array}{l}\text { Pre-treatment } \\
\text { (mg/kg, i.p.) }\end{array}$} & \multirow{2}{*}{ Rats } & \multicolumn{5}{|c|}{ Onset time (mean $\pm S E M$ in seconds) } & \multirow{2}{*}{$\begin{array}{l}\text { No extensor } \\
\text { seizures }\end{array}$} \\
\hline & & & & Tonic limb flexion & Tonic extensor & Clonus & Stupor & Recovery & \\
\hline 1 & Group A (control) & $3 \%$ gum acacia & 6 & $5.5 \pm 0.428$ & $12.5 \pm 0.4282$ & $5.333 \pm 0.421$ & $139 \pm 5.526$ & $162.33 \pm 5.590$ & 0 \\
\hline 2 & Group $B_{1}$ (test 1 ) & EECM 50 & 6 & $4.833 \pm 0.307$ & $5.5 \pm 0.223^{\mathrm{a}}$ & $4.333 \pm 0.614$ & $146 \pm 7.479$ & $160.67 \pm 7.269$ & 0 \\
\hline 3 & Group $\mathrm{B}_{2}^{1}$ (test 2) & EECM 100 & 6 & $4.5 \pm 0.223$ & $3.833 \pm 0.307^{a}$ & $4.5 \pm 0.428$ & $125.83 \pm 2.535$ & $138.67 \pm 2.716^{a}$ & 0 \\
\hline 4 & Group B (test 3) & EECM 200 & 6 & $4 \pm 0.258^{\mathrm{a}}$ & $2.167 \pm 0.307^{\mathrm{a}}$ & $4.667 \pm 0.666$ & $124.50 \pm 4.958$ & $135.33 \pm 5.044^{\mathrm{a}}$ & 0 \\
\hline 5 & Group C (standard) & Phenytoin 25 & 6 & $3.5 \pm 0.223^{\mathrm{a}}$ & $0^{\mathrm{a}}$ & $4.667 \pm 0.494$ & $114.33 \pm 3.169^{\mathrm{a}}$ & $122.50 \pm 3.096^{a}$ & 6 \\
\hline \multirow[t]{3}{*}{$\mathrm{p}$} & & $\mathrm{F}$ & & 6.625 & 268.49 & 0.506 & 6.176 & 11.658 & \\
\hline & & df & & 4.25 & 4.25 & 4.25 & 4.25 & 4.25 & \\
\hline & & $\mathrm{P}$ & & $<0.01$ & $<0.01$ & $>0.05$ & $<0.01$ & $<0.01$ & \\
\hline
\end{tabular}

$\mathrm{N}=6$ in each group; all the values were expressed in mean \pm SEM. ${ }^{\mathrm{a}} \mathrm{p}<0.01$ is significant when compared with control (ANOVA followed by Dunnett's multiple comparison test). MES: Maximal electroshock seizure, EECM: Ethanolic extract of Citrus maximus, SEM: Standard error of mean, i.p.: Intraperitoneal

Table 2: PTZ-induced seizure model

\begin{tabular}{lllllll}
\hline $\begin{array}{l}\text { S. No. } \\
\text { Number of } \\
\text { animals }\end{array}$ & $\begin{array}{l}\text { Pre-treatment } \\
\text { (mg/kg, i.p.) }\end{array}$ & $\begin{array}{l}\text { Latency } \\
\text { (Seconds } \pm \text { SEM) }\end{array}$ & $\begin{array}{l}\text { Number of } \\
\text { convulsions }\end{array}$ & $\begin{array}{l}\text { Average duration of convulsions } \\
\text { (Seconds } \pm \text { SEM) }\end{array}$ & $\begin{array}{l}\text { Number of animals } \\
\text { recovered }\end{array}$ \\
\hline 1 & 6 & $3 \%$ gum acacia & $670.33 \pm 25.43$ & $1.677 \pm 0.210$ & $14.583 \pm 0.374$ & 6 \\
2 & 6 & EECM 50 & $1305.2 \pm 37.92$ & 1 & $9.5 \pm 0.428$ & 6 \\
3 & 6 & EECM 100 & $1610.5 \pm 28.40$ & 1 & $7.667 \pm 0.557$ & 6 \\
4 & 6 & EECM 200 & $2090 \pm 37.3$ & 1 & $5.333 \pm 0.494$ & 6 \\
5 & 6 & Diazepam 4 & - & 0 & - & 6 \\
One-way ANOVA & & F & 330.07 & 40 & 70.298 & \\
& & df & $3.20<0.01$ & $4.25<0.01$ & $3.20<0.01$ & \\
\hline
\end{tabular}

$\mathrm{N}=6$ in each group; all the values were expressed in mean \pm SEM. $\mathrm{P}<0.01$ is significant when compared with control (ANOVA followed by Dunnett's multiple comparison test). PTZ: Pentylenetetrazol, EECM: Ethanolic extract of Citrus maximus, SEM: Standard error of mean, i.p.: Intraperitoneal 
$11.6 \pm 0.40$ seconds, and Achliya et al. [12] as $14.39 \pm 0.52$ seconds in their respective control groups. The extensor phase in the three test groups, viz., Group $B_{1}, B_{2}$, and $B_{3}$ were found to be $5.5 \pm 0.2236,3.833 \pm 0.3073$, and $2.167 \pm 0.3073$ seconds, respectively, which shows there was a reduction in its duration.

There was complete abolition of the extensor phase in the standard group of phenytoin. Similar effects were found with different doses of phenytoin by Chattopadhyay et al. [13], where there was reduction in the extensor phase of MES-induced convulsion. Phenytoin sodium exerts an antiepileptic effect by stabilization of the neuronal membrane, and thus, prolongation of recovery of inactivated sodium channels. On high doses, phenytoin can also block the calcium influx during depolarization [14]. There was a $0 \%$ incidence of mortality of rats in all the groups, which correspond to the findings of Sonavane et al. [15].

From the above findings, it can be said that the EECM leaves reduced the extensor phase of convulsion in the dose-dependent manner [16] with maximum effect seen at the dose of $200 \mathrm{mg} / \mathrm{kg}$.

The seizure is produced by the PTZ-induced seizure model resembles in the absence or petit mal seizure in human beings. A drug which causes either delay or complete abolition of convulsions in the PTZ-induced seizure model has reportedly got anticonvulsant activity [7].

In the present study, latency to convulsion in the control group was $670.33 \pm 25.438$ seconds, and for the test groups $\mathrm{B}_{1}, \mathrm{~B}_{2}$, and $\mathrm{B}_{3^{\prime}}$, it was found to be $1305.2 \pm 37.926,1610.5 \pm 28.402$, and $2090 \pm 37.3$ seconds, respectively, which shows an increase in the latency with increasing dose. In the standard group of diazepam ( $4 \mathrm{mg} / \mathrm{kg})$, there was complete absence of convulsions within the specified time of 60 minutes of observation after subcutaneous PTZ injection [6], which corresponds to the findings of Khosla and Pandhi [17], for their standard group (diazepam, $4 \mathrm{mg} / \mathrm{kg}$ ) and Sonavane et al. [15]. There were convulsions in all $(100 \%)$ the animals in the control and test groups of EECM, which correlates with the findings of Abed [18]. The incidence of convulsions in the control group of Ambawade et al. [19] was also found to be $100 \%$. The number of convulsions in all the test groups was found to be 1 , whereas it was $1.677 \pm 0.2108$ in the control group.

The average duration of convulsions in the control Group A and the test groups $\mathrm{B}_{1}, \mathrm{~B}_{2}$, and $\mathrm{B}_{3}$ was $14.583 \pm 0.3745,9.5 \pm 0.4282,7.667 \pm 0.5578$, and $5.333 \pm 0.4944$ seconds, respectively, which shows a decrease in the duration of convulsions with increasing dose. Animals were observed for 30 minutes to detect the onset of spasm and generalized tonic-clonic seizures and further up to $2 \mathrm{hr}$ to detect mortality if any [20] animals devoid of seizures were considered as protected [21]. In this model of seizure, also it was found that there was no mortality of rats in any of the groups, and the maximum anticonvulsant activity was found with the $200 \mathrm{mg} / \mathrm{kg}$ dose.

Thus, from the above two seizure models of MES and PTZ, it can be concluded that EECM leaves have got an anticonvulsant effect in the increasing dose-dependent manner.

\section{CONCLUSION}

Thus, the present study showed that EECM leaves have got significant anticonvulsant effect, and it would be of great value to confirm these findings for different other doses and to find the exact mechanism of action with further studies on experimental animals and finally doing clinical studies to make it available for use in human beings in a commercial way. With the change in the global scenario toward the use of non-toxic herbal and ayurvedic medicines, development of more purified forms of $C$. maximus leaf extract should be emphasized for the control of seizures in the future.

\section{REFERENCES}

1. Lowenstein DH. Diseases of the Central Nervous System. Seizures and Epilepsy. In: Kasper DL, Braunwald E, Fauci AS, Hauser SL, Longo DL, Jameson J, editors. Harrison's Principles of Internal Medicine. $16^{\text {th }}$ ed., Vol. 2. New York: The McGraw-Hill Companies, Inc.; 2005. p. 2357-70.

2. Online Archive of Novice Baker, Just another Wordpress.com weblog. UK: Packt Publishing; 2006 Aug 16. Available from: http://novicebaker. wordpress.com/2006/08/16/pomelo/. [Last cited on 2008 Sep 16].

3. Database of www.PomeloFruit.cn. Xiamen, China: Dooyi Growth and Agriculture Co., Ltd.; 2007. Available from: http://www.pomelofruit. $\mathrm{cn} /$. [Last cited on 2008 Oct 25]

4. Remington. Solution, emulsion, suspension and extracts. The Science and Practice of Pharmacy. $19^{\text {th }}$ ed. Pennsylvania: Mack Publishing Company; 1995. p. 1495-523.

5. OECD (Organization for Economic Cooperation and Development) Section 4, Health Effects: Test No. 425: Acute Oral Toxicity: Upand-Down Procedure. OECD Guidelines for Testing of Chemicals. France: OECD Publishing; 2006 July 11. p. 1-27. Available from: $\mathrm{http}: / / \mathrm{www}$. oecdbookshop.org/oecd/index.asp?lang=en. [Last cited on 2008 September 27; Adopted on 2006 March 23].

6. Gerhard VH. Psychotropic and neurotropic activity. Drug Discovery and Evaluation, Pharmacological Assays. $2^{\text {nd }}$ ed. Berlin: Springer; 2002. p. 401-94.

7. Kulkarni SK. Experiments on Intact Preparations. Pharmacology of CNS. Hand Book of Experimental Pharmacology. $3^{\text {rd }}$ ed. reprint. New Delhi: Vallabh Prakashan; 2005. p. 131-9.

8. Ha JH, Lee DU, Lee JT, Kim JS, Yong CS, Kim JA, et al. 4-Hydroxybenzaldehyde from Gastrodia elata B1. Is active in the antioxidation and GABAergic neuromodulation of the rat brain. J Ethnopharmacol 2000;73(1-2):329-33.

9. Singh D, Maurya VB, Prajapati K, Kumar H, Niranjan PS, Jain SK. Evaluation of anticonvulsant activity of the leaves ethanolic and aqueous extracts of Nyctanthes arbortristis Linn. Against seizures induced by pentylenetetrazole and electroconvulsive shock in mice. Int J Pharm Sci Res 2010;1(2):63-8.

10. Manocha A, Sharma KK, Mediratta PK. Anticonvulsant effect of nalbuphine on maximal electroshock seizure in mice. Indian $\mathrm{J}$ Pharmacol 1998;30:306-10.

11. Rewari S, Prabhu S. A comparative experimental study of proconvulsive potential of Fluoroquinolones. Indian J of Pharmacol. 1999;31:29-32.

12. Achliya GS, Wadodkar SG, Dorle AK. Evaluation of CNS activity of Brahmi ghrita. Indian J Pharmacol 2005;37(1):33-6.

13. Chattopadhyay RN, Chaudhuri S, Roy RK, Mandal S, Lahiri HL, Maitra SK. Potentiation of antiepileptic activity of phenytoin by calcium channel blockers against maximal electroshock seizure in mice. Indian J Pharmacol 1998;30(5):326-8.

14. McLean MJ, Macdonald RL. Multiple actions of phenytoin on mouse spinal cord neurons in cell culture. J Pharmacol Exp Ther 1983;227(3):779-89.

15. Sonavane GS, Palekar RC, Kasture VS, Kasture SB. Anticonvulsant and behavioural actions of Myristica fragrans seeds. Indian J Pharmacol 2002;34:332-8.

16. Pushpa VH, Shetty KP, Sushma N, Kalabaharathi HL, Satish AM. Evaluation of the anticonvulsant activity of ethanol extract of Psidium guajava (guava leaves) in albino mice. Int J Pharm Sci Res 2014;5(10):4288-92.

17. Khosla P, Pandhi P. Anticonvulsant effect of nimodipine alone and in combination with diazepam on PTZ induced status epilepticus. Indian J Pharmacol 2001;33:208-11.

18. Abed TW. Differential effects of diphenylhydantoin and di-npropylacetate on the protective activity of diazepam against chemicallyinduced convulsions in mice. Indian J Pharmacol 1995;27:111-5.

19. Ambawade SD, Kasture VS, Kasture SB. Anticonvulsant activity of roots and rhizomes of Glycyrrhiza glabra. Indian J Pharmacol 2002;34(4):251-5.

20. Arulmozhi DK, Veeranjaneyula SL, Bodhankar, SR. Pharmacological studies of the aqueous extract of Sapindus trifoliationsan central nervous system: Possible antimigrane mechanisms. J Ethnopharmacol 2005;97:491-6.

21. Adzu B, Amos S, Mauzzam I, Inyang US and Gamaniel KS: Neuropharmacological Screening of Diospyres mespiliformis in mice. J Ethnopharmacol 2000;83:139-43. 